\title{
Influencing Factors of Smart Community Service Quality: Evidence from China
}

\author{
Fengke WANG, Juzheng ZHANG, Panke ZHANG*
}

\begin{abstract}
Smart community is an important constituent part of a smart city and an extension and deepening of the concept of the latter. When it comes to smart community, the digitalization upgrading of traditional community service is conducted via information technology, in an effort to improve the service experience of community residents and elevate their happiness index. From social functions, smart community also has the advantages in facilitating the smart transformation of cities, promoting the harmonious society construction, and improving governmental efficiency and image, among others. However, various problems persist in the construction and development process of a smart community, such as mismatching service contents and low service quality. To explore the influencing factors of smart community service quality, a total of 16 influencing factors were extracted from 5 dimensions: service object, service subject, government role, management system, and service content. The relationships among the influencing factors were analyzed via the decision-making trial and evaluation laboratory (DEMATEL)-interpretative structural modeling (ISM) composite model, and a multi-order explanation model was constructed for these influencing factors. Result shows that the legal guarantee is the root cause influencing the smart community service quality. Development standard, basic service, and expected service are deep influencing factors that play mediating roles. Middle-layer factors such as service and operating systems have a direct bearing on quality perception. The surface-layer factors directly decide residential assessment on the smart community service quality. This study has also manifested the feasibility of the integrated DEMATEL-ISM method in analyzing the action mechanism of influencing factors for smart community service quality, providing a new analytical idea and modeling method for the smart community service quality.
\end{abstract}

Keywords: community service quality; DEMATEL-ISM; influencing factor; smart community

\section{INTRODUCTION}

The community, as the most important place where urban residents live and the basic unit of urban management, plays a very significant role in urban governance. Since the advent of the new era, the complexity of community resident needs has posed new requirements for urban community governance [1]. The concept of smart community was born rightly under this background. In this study, we define smart community as a community model that provides high-quality new service content for community residents through new information technology (5G, blockchain, etc.), so as to improve the happiness index of community residents. From the functional level, a smart community serves community residents and provides efficient, safe, and smart service contents. An example is establishing a property management system conforming to the community reality according to its characteristics to realize the fully automated management of parking lots, access control, and long-distance payment, to name a few. This proposition not only can enhance the sense of safety of community residents, save time for both residents and property management company but can also realize the concentrated operation management and reduce the property operating cost. Moreover, the development path of new-type cities can be further sought for through the smart community construction [2]. However, problems such as mismatching demands and shortage of funds continue in the practical smart community construction process [3-5]. The cognition degree of smart community is generally not high, and some people may even totally lack understanding of it. The service quality of smart community which is a newtype community management mode, is not only influenced by objective environmental factors such as local policies, resource conditions, and urban economic status but also by subjective factors such as resident background, community management mode, and community service personnel. Additionally, these factors are intricate and interact with one another. Therefore, identifying and distinguishing the factors influencing the smart community service quality and analyzing the influence and action mechanisms between the factors constitute the foundation for improving the smart community service quality and driving the smart community and smart city construction.

However, many present studies on the smart community service quality have concentrated on the community public service supply, information technology, and network platform construction, to name a few [6-8]. Moreover, many research contents have set the background, consequently lacking universality [9]. Few studies have involved management factors such as participatory governance, operating system, service system, and subjective human factors such as quality perception, service expectation, professional quality, and professional value, which result in such events. Most mechanism studies on the smart community service quality have mostly substituted the subjective modeling into the concrete community service quality events to explore the factors influencing the community service quality under a single background but neglected the interaction between influencing factors and their action mechanism.

Therefore, the influencing factors were screened and extracted from multiple dimensions such as personnel, management, and service. The interactions between the factors and the overall action mechanism were analyzed; their influencing degrees were clarified; and the surfacelayer, middle-layer, deep-layer, and root influencing factors were distinguished. Moreover, the concrete action path between factors was extracted, and the corresponding suggestions were proposed. This study has profound practical significance for contributing to the smart community construction and improving the smart community service quality.

\section{STATE OF THE ART}

Most studies on community service quality have aimed at the community public service, combined the practical cases to analyze the problems existing in the community 
public service, and discussed the factors leading to these problems. Taking Junmen community in Fuzhou City of China as an example, Yang and Liu [10] specifically investigated the problems in this community, including low utilization efficiency of public service resources and poor feedback from community residents and then put forward their suggestions for improvement. Wang et al. [11] highlighted that the weakness existing in the community public service was caused by the imbalance of governance and proposed that the governance of community public service should be more refined. He and Shao [12] constructed a new three-dimensional model of smart supply by virtue of information integration technologies such as big data and cloud platform, helping communities to realize precise supply behaviors. Directing at the rural water management mode, Hutchings et al. [13] collected and analyzed 174 successful community management cases and proposed that the effective community management was highly affected by the collective initiative, community leadership, and institutional transparency.

As a new-type community development direction, the management model of smart community has always been a research hotspot among relevant scholars. By studying four practical cases in Malawi Region, Chowns [14] found that although community governance exerted an "effect" on the state (and donator), the technology and financial performances under the community governance were not as outstanding as expected. From the angle of the system, Qian [15] deemed that the management could be facilitated by intelligence technology. Goethem et al. [16] stated that the quality of community service was a key factor influencing adolescents' willingness to participate in community public service. Crittenden and Everson [17] further stressed the importance of community governance during the COVID-19 global pandemic.

A smart community can provide safe and convenient smart services by using hardware equipment and information technology according to users' needs and preferences [18]. As the development basis of smart communities, every update of technology will promote the improvement of community service quality. Lee et al. [19] constructed a new-type smart home management system, which could effectively integrate community services, avoid waste of resources, and deepen the fusion of communities with the surrounding environment. Abeysiriwardhana W. et al. [20] stated that smart community uses information technology to manage the infrastructure of the community, and proposed a softwarebased edge computing node, namely the smart community edge (SCE), to help develop smart community service platform. Farooqi N. et al. [21] further emphasized the importance of smart city construction for future urban development and the mutual promotion between smart city and smart community, proposed an ideal composition state of smart community, and respectively demonstrated the difficulties related to ICT and IoT in terms of technology and policy.

To sum up, scholars have mostly concentrated on the case analysis, governance model, and technology application, among others, during their investigation on smart community services. They also believed that the community management mode, service content, and resource utilization, to name a few, will affect the objective quality of smart community services. However, little attention has been paid to the comprehensive action mechanism of influencing factors, and most of the existing studies have been partial to mathematical statistics and practical case analysis. Moreover, research on the interaction between influencing factors and influence mechanism has lacked adequate rigor.

Therefore, to overcome the deficiencies of the existing research, the literature and Delphi methods were used to determine the influencing factors of smart community service quality and subsequently redefine them. The cause degree and centrality of each influencing factor were calculated through the DEMATEL method, and the degrees of influence and importance of each factor on and to the smart community service quality were determined. The ISM method was used to filter the weak influence paths. An interpretative structural model was constructed for the smart community service quality, and then the influence path and influence level of each factor were clarified. These processes facilitated the construction of smart communities and improvement of community services.

The remainder of this study is organized as follows. Section 3 introduces the extraction process of influencing factors for the smart community service quality and model calculation process. Section 4 analyzes the calculation results. Section 5 presents the calculation results and management suggestions. Section 6 summarizes the research contents.

\section{METHODOLOGY}

\subsection{Extraction Method of Influencing Factors}

The extraction of influencing factors is the basis for analyzing the influence mechanism of smart community service quality, and the influencing factors are generalized into aspects such as personnel, management, service, and environment, to name a few [3]. In this study, the community personnel were divided into two parts: service provider and service receiver $[10,11]$. The management dimension refers to the set of management models adopted by the community administrators or relevant government sectors for smart community services [14]. Service dimension means the concrete service content provided by the smart community or the pattern of manifestation [11, 12].

According to the above literature review, the influencing factors were finally extracted using the literature method after repeated communication with the expert group. In the division process of index system, the pure technical factors were excluded. Based on the existing research results and interview results, 5 first-level indexes and 16 second-level indexes were raised as seen in Tab. 1.

(1) Dimension of service object:

As a novel community management model, smart community aims to improve the happiness of community residents on the basis of the satisfaction of their basic needs by providing high-quality digital services. Considering the subjective factors such as diversity needs of residential and special needs under different circumstances, the three influencing factors in the dimension of service object were 
summarized following the research of other scholars and interview results.

Table 1 Collection of influencing factors of smart community service quality

\begin{tabular}{|c|c|}
\hline Dimension of service object & Quality perception A1 \\
\cline { 2 - 2 } & Service expectation A2 \\
\cline { 2 - 2 } Dimension of service subject & Reasonability of charges A3 \\
\cline { 2 - 2 } Dimension of government role & Professional quality A4 \\
\cline { 2 - 2 } & Professional value A5 \\
\cline { 2 - 2 } & Legal guarantee A6 \\
\hline Dimension of management & Development standard A7 \\
\cline { 2 - 2 } system & Resource support A8 \\
\cline { 2 - 2 } & Participatory governance A10 \\
\cline { 2 - 2 } & Service system A11 \\
\cline { 2 - 2 } & Operating system A12 \\
\hline Dimension of service content & Basic service A13 \\
\cline { 2 - 2 } & Digital service A14 \\
\cline { 2 - 2 } & Expected service A15 \\
\cline { 2 - 2 } & Service tangibility A16 \\
\hline
\end{tabular}

Quality perception. In this study, an important factor differentiating smart community service from traditional service is the greater emphasis laid by users on the perception of added values when enjoying the services, such as respect, satisfaction, and happiness. Through the interview with community residents, this study believed that the past community experience of residents would generate a considerable effect on quality perception.

Service expectation. The resident perception for community services relied upon the speculation on the services. If the service quality perceived by a proprietor deviates from the expected service quality, the proprietor may break away from such service and hold a negative attitude toward the community service, thus affecting owners' perception for the latter. Meanwhile, if the service quality of the community reaches the proprietor's expectation, it does not mean that the proprietor will hold a positive attitude.

Reasonability of charges. Some scholars have paid special attention to the public service supply problem in community governance. However, some community services will certainly be antagonistic to the community residents. The most important divergence lies in the reasonability of charges. In the early-stage survey, we found that Chinese residents paid extra attention to the reasonability of property management fee.

(2) Dimension of service subject:

Professional quality. As direct providers of community service, the professional abilities of community service personnel have a direct bearing on the objective quality of services. Especially with the popularization of high technology in community services, the service personnel should improve their working skills (e.g., Mandarin Chinese, network operation) and provide proprietors with better services. Meanwhile, some scholars also suggested that the community administrators should cultivate the ability to mediate conflicts [22].

Professional value. The satisfaction of community service personnel with social and personal attributes (e.g., taking pleasure in helping people and career planning) in the working process can enhance their willingness to provide services, improve service quality, and influence the users' perception.

(3) Dimension of government role:
As an important constituent part of public service, community service is generally supervised by the local government. However, the functional role of government has been transformed from administrator into supporter and supervisor with the continuous smart community construction [23].

Legal guarantee. A perfect legal system is believed in this study to be an important system guarantee for the orderly smart community construction. The construction of some functions for smart communities which serve as a new community management model in China remains to be in the exploration phase. The perfect legal system is an important guarantee for improving the community service level and compensating for the "weaknesses" of China's smart community construction.

Development standard. According to this study, the relevant standard of community service decides the lower limit of community service quality. China's community services conform to two standards: (1) Legal standard: Constitution of the People's Republic of China and Property Law of the People's Republic of China as well as the relevant contents of laws, regulations, and standards with legal force such as Measures for the management of property service charge; (2) Property service standard: In China, property is a direct provider and administrator of community service. Effective and feasible service standard and incentive mechanism can effectively mobilize employees' working enthusiasm and remarkably improve service quality, such as Standardization Law of the People's Republic of China and other service standards.

Resource support. In the smart community construction and management process, the most important government function is to provide resources for communities, including data support, talent introduction and education, supervision, and management, among others [24].

(4) Dimension of management system:

Development theme. During the smart city construction, China has emphasized the construction concept that "each city has its unique characteristics." Moreover, the excessive standardization of a city is thought to impede its development. For some scholars, the smart community construction should have its own development theme and style, such as sustainable, environmentally friendly, and high intelligence [25].

Participatory governance. The participatory governance mentioned in this study refers to community residents' participation in community management. Some researchers have pointed out the importance of participatory governance to the improvement of residents' satisfaction [26, 27]. In this study, the antagonism between residents and staffs in the community management is ascribed to information asymmetry which leads to their identity exchange. The residents participating in the community management can effectively remit the information barriers, increase the perception channels of proprietors, and improve service quality. However, some scholars deemed that participatory governance needs other guarantees; otherwise, it will hinder the enthusiasm of residents for participatory governance [28].

Service system. The smart community service system is a set of subsystems providing services for the residents, including operation layer, and management layer, among 
others. It affects resident perception through the big data analysis of community residents.

Operating system. As the population aging is aggravated in China, how to let the aged enjoy highly intelligent community services has become a very important question. The APP-represented intelligent platforms constitute the main channel taken by smart community residents to enjoy services, and the convenience of operating system largely influences users' service experience [29]. Therefore, improvement of this factor can effectively promote the perception of residents (especially old residents).

(5) Dimension of service content:

Basic service (essential service). It is a set of the most fundamental services provided by communities, including greening, access control, sanitation, firefighting, traffic, among others [30].

Digital service. Different from the traditional community, a distinct feature of a new-type smart community is the application of digital technology, which has broken through the traditional communication disorder between residents and property management company, shortened their communication distance, and played a crucial role in improving the communication quality and perception ability of residents and the service quality.

Expected service. It refers to special service contents (e.g., psychological guidance and assistance in communication) expected by residents from the community which can bring them satisfaction and happiness, with strong subjectivity [31, 32]. This study proposes that the satisfaction of similar services can effectively improve the perception of residents for community services.

Service tangibility. Tangible community service is a means of service that enables community residents to perceive community services more easily through hardware facilities (e.g., automatic locker, self-help access control), service environment, and administrator behaviors, among others. This factor is not especially important but exerts a certain effect on improving the service perception of residents.

\subsection{Modeling Method for Influencing Factors of Smart Community Service Quality}

(1) Modeling method and process:

DEMATEL and ISM are two common methods in the structural modeling system, both of which are able to effectively process complex systems. The former tends to process the influence relation between factors in a complex system and determine the causal and result factors through the calculation. ISM can divide a complex system into several subsystems. By decomposing a complex system, a multilayered structural model reflecting the concrete operation mechanism of this system can be established. The organic combination of the two is called DEMATELISM model which can more effectively determine the key factors, influence hierarchy, and influence degree in the complex system. This composite model is very scientific and has been widely applied to fields such as project management, technology control, and management practice [33-35]. Fig. 1 illustrates the concrete calculation process.
(2) Establishment of direct impact matrix:

The influence intensities between the factors were determined using the Delphi method and Likert five-point scale. The influencing factors were denoted as $\operatorname{Ai}(i=1,2$, $3, \ldots, 16)$ according to the order of dimension. The influence level between every two factors was defined as very strong (4 scores), strong (3 scores), ordinary (2 scores), weak (1 score), and no influence ( 0 score). Three property management personnel, three community grassroots service personnel, and four scholars working in the field of community services were invited to form an expert group. Through repeated communications with the expert group, the influencing factors of smart community service quality were confirmed. According to the scoring results given by the expert group, a direct impact matrix was constructed.

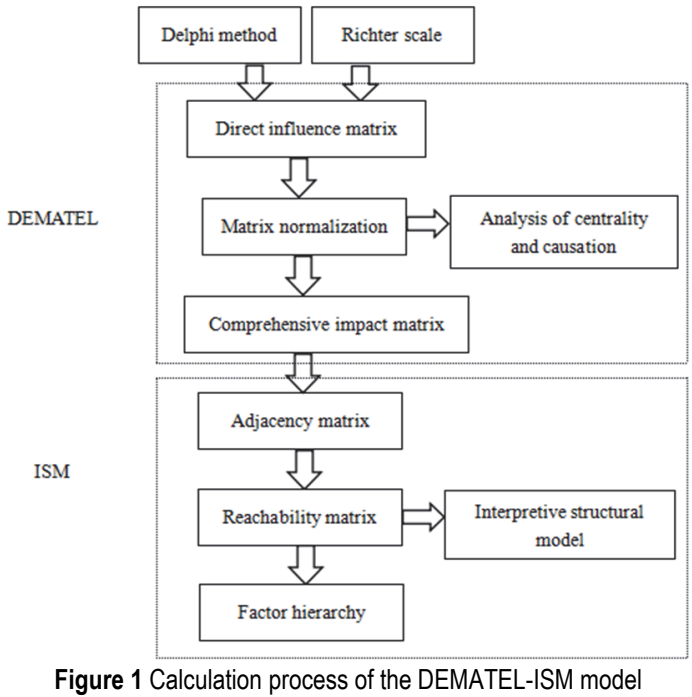

(3) Establishment of total impact matrix:

The direct impact matrix $\boldsymbol{X}$ is standardized to obtain the normalized impact matrix $\boldsymbol{D}$.

$\boldsymbol{D}=\left(\frac{1}{\operatorname{Max}_{i=1}^{n} \sum_{j=1}^{n} a_{i j}}\right) * \boldsymbol{X}$

The normalized impact matrix $\boldsymbol{D}$ is further processed to obtain the total impact matrix $\boldsymbol{T}$.

$\boldsymbol{T}=\boldsymbol{D} *(\boldsymbol{I}-\boldsymbol{D})^{-1}$

(4) Calculation of cause and centrality:

Each factor was calculated and analyzed through the total impact matrix $\boldsymbol{T}$. The values in each row are added. The result obtained is rightly the degree to which this factor is influenced by other factors and is called, influence degree $R$. The values in each column are added. The result acquired is the overall influence degree of this factor on other factors and is called the influenced degree $C$. The $R$ and $C$ values of one factor are added to obtain the centrality $F$. The $C$ value is deducted from the $R$ value of one factor, thus obtaining the cause $J$.

(5) Establishment of reachable matrix: 
Threshold $\lambda$ is the first and the most important step to establish the reachable matrix and is directly related to the model construction and extraction of factor relationships. The data were further logically judged through the following formula, and the total impact matrix $\boldsymbol{T}$ is transformed into the adjacency matrix $\boldsymbol{K}$. The reachable matrix $\boldsymbol{U}$ is obtained by iterating the adjacency matrix $\boldsymbol{K}$.

$$
\begin{aligned}
t_{i j} & \geq \lambda(i, j=1,2, \ldots, n), k_{i j}=1 \\
t_{i j} & \leq \lambda(i, j=1,2, \ldots, n), k_{i j}=0
\end{aligned}
$$

(6) Establishment of interpretative structural model

After the reachable matrix $\boldsymbol{U}$ was established, three subsets should be determined, namely, reachable set $R i$, antecedent set $Q i$, and intersection set $Y i$.

Reachable set $R i$ is the set of column factors corresponding to the matrix factors containing 1 in the row where factor $A i$ exists in the reachable matrix $\boldsymbol{U}$, meaning the factor that will be reached by $A i$.

Antecedent set $Q i$ is the set of row factors corresponding to the matrix factors containing 1 in the column where the factor $A i$ exists in the reachable matrix $\boldsymbol{U}$. It represents other elements that will arrive at $\mathrm{Ai}$.
Intersection set $Y i$ is the intersection set between reachable and antecedent sets, namely, $Y i=R i \cap Q i$.

If $R(A i)=R(A i) \cap Q(A i)$, the factor corresponding to $A i$ is bottom-layer influencing factor. The row and column where this factor belongs are deleted, and this operation is repeated until the levels of all factors are determined.

\section{RESULT ANALYSIS \\ 4.1 Calculation OF Centrality and Cause}

To avoid algorithm invalidation, the integral part of calculation result was reserved, the influence intensities between factors were determined, and the direct impact matrix $\boldsymbol{X}$ was constructed as seen in Tab. 2 .

The direct impact matrix $\boldsymbol{X}$ was processed through Eq. (1) and Eq. (2) to obtain the total impact matrix $\boldsymbol{T}$ as seen in Tab. 3.

The influence degree, influenced degree, centrality, and cause degree of each factor were calculated according to the total impact matrix $\boldsymbol{T}$. Tab. 4 lists the overall calculation results.

The calculation results of influencing factors were further visualized, and a scatter diagram was constructed in Fig. 2.

Table 2 Direct impact matrix $\boldsymbol{X}$

\begin{tabular}{|c|c|c|c|c|c|c|c|c|c|c|c|c|c|c|c|c|c|}
\hline & $\mathrm{A} 1$ & $\mathrm{~A} 2$ & $\mathrm{~A} 3$ & $\mathrm{~A} 4$ & $\mathrm{~A} 5$ & $\mathrm{~A} 6$ & $\mathrm{~A} 7$ & $\mathrm{~A} 8$ & $\mathrm{~A} 9$ & $\mathrm{~A} 10$ & $\mathrm{~A} 11$ & $\mathrm{~A} 12$ & $\mathrm{~A} 13$ & $\mathrm{~A} 14$ & $\mathrm{~A} 15$ & $\mathrm{~A} 16$ \\
\hline $\mathrm{A} 1$ & 0 & 0 & 1 & 0 & 0 & 0 & 0 & 0 & 0 & 1 & 0 & 0 & 0 & 0 & 0 & 1 \\
\hline A2 & 3 & 0 & 1 & 0 & 0 & 0 & 0 & 1 & 0 & 2 & 0 & 0 & 0 & 0 & 1 & 1 \\
\hline A3 & 0 & 4 & 0 & 0 & 0 & 0 & 0 & 1 & 0 & 4 & 1 & 1 & 3 & 1 & 1 & 0 \\
\hline A4 & 4 & 0 & 4 & 0 & 0 & 0 & 0 & 0 & 0 & 2 & 0 & 0 & 0 & 0 & 0 & 0 \\
\hline A5 & 2 & 0 & 0 & 4 & 0 & 0 & 0 & 0 & 0 & 0 & 0 & 0 & 0 & 0 & 0 & 0 \\
\hline A6 & 0 & 2 & 3 & 0 & 0 & 0 & 4 & 4 & 4 & 4 & 3 & 3 & 3 & 2 & 2 & 0 \\
\hline A7 & 0 & 4 & 4 & 0 & 0 & 0 & 0 & 0 & 3 & 0 & 1 & 1 & 3 & 0 & 0 & 0 \\
\hline A8 & 0 & 0 & 3 & 0 & 0 & 0 & 0 & 0 & 0 & 0 & 1 & 1 & 4 & 1 & 1 & 1 \\
\hline A9 & 0 & 2 & 3 & 0 & 0 & 0 & 4 & 0 & 0 & 0 & 0 & 0 & 2 & 2 & 3 & 2 \\
\hline A10 & 4 & 0 & 0 & 0 & 0 & 0 & 0 & 0 & 0 & 0 & 4 & 4 & 1 & 0 & 3 & 0 \\
\hline A11 & 4 & 0 & 0 & 0 & 0 & 0 & 0 & 0 & 0 & 4 & 0 & 4 & 0 & 0 & 0 & 4 \\
\hline A12 & 4 & 0 & 0 & 0 & 0 & 0 & 0 & 0 & 0 & 3 & 4 & 0 & 0 & 4 & 0 & 4 \\
\hline A13 & 4 & 0 & 4 & 0 & 0 & 0 & 0 & 2 & 3 & 0 & 0 & 0 & 0 & 1 & 2 & 3 \\
\hline A14 & 4 & 0 & 2 & 0 & 0 & 0 & 0 & 0 & 0 & 4 & 4 & 4 & 0 & 0 & 0 & 4 \\
\hline A15 & 3 & 4 & 4 & 0 & 0 & 0 & 0 & 0 & 3 & 0 & 0 & 0 & 0 & 0 & 0 & 2 \\
\hline A16 & 4 & 0 & 0 & 0 & 0 & 0 & 0 & 0 & 0 & 4 & 3 & 2 & 0 & 0 & 3 & 0 \\
\hline
\end{tabular}

\begin{tabular}{|c|c|c|c|c|c|c|c|c|c|c|c|c|c|c|c|c|}
\hline & $\mathrm{A} 1$ & $\mathrm{~A} 2$ & A3 & A4 & A5 & A6 & A7 & A8 & A9 & $\mathrm{A} 10$ & A11 & $\mathrm{A} 12$ & A13 & A14 & A15 & A16 \\
\hline A1 & 0.01 & 0.00 & 0.03 & 0.00 & 0.00 & 0.00 & 0.00 & 0.00 & 0.00 & 0.04 & 0.01 & 0.01 & 0.00 & 0.00 & 0.01 & 0.03 \\
\hline A2 & 0.11 & 0.01 & 0.04 & 0.00 & 0.00 & 0.00 & 0.00 & 0.04 & 0.00 & 0.07 & 0.02 & 0.02 & 0.01 & 0.01 & 0.04 & 0.04 \\
\hline A3 & 0.07 & 0.13 & 0.03 & 0.00 & 0.00 & 0.00 & 0.00 & 0.04 & 0.01 & 0.15 & 0.07 & 0.07 & 0.10 & 0.04 & 0.06 & 0.04 \\
\hline A4 & 0.14 & 0.02 & 0.13 & 0.00 & 0.00 & 0.00 & 0.00 & 0.01 & 0.00 & 0.09 & 0.02 & 0.02 & 0.01 & 0.01 & 0.01 & 0.01 \\
\hline A5 & 0.08 & 0.00 & 0.02 & 0.12 & 0.00 & 0.00 & 0.00 & 0.00 & 0.00 & 0.01 & 0.00 & 0.00 & 0.00 & 0.00 & 0.00 & 0.00 \\
\hline A6 & 0.12 & 0.12 & 0.16 & 0.00 & 0.00 & 0.00 & 0.14 & 0.14 & 0.15 & 0.20 & 0.16 & 0.16 & 0.14 & 0.11 & 0.12 & 0.09 \\
\hline A7 & 0.05 & 0.15 & 0.15 & 0.00 & 0.00 & 0.00 & 0.01 & 0.02 & 0.10 & 0.04 & 0.05 & 0.05 & 0.10 & 0.02 & 0.03 & 0.04 \\
\hline A8 & 0.05 & 0.02 & 0.12 & 0.00 & 0.00 & 0.00 & 0.00 & 0.01 & 0.02 & 0.04 & 0.06 & 0.05 & 0.13 & 0.04 & 0.05 & 0.06 \\
\hline A9 & 0.06 & 0.10 & 0.13 & 0.00 & 0.00 & 0.00 & 0.12 & 0.01 & 0.03 & 0.05 & 0.04 & 0.03 & 0.09 & 0.07 & 0.11 & 0.11 \\
\hline A10 & 0.18 & 0.02 & 0.02 & 0.00 & 0.00 & 0.00 & 0.00 & 0.00 & 0.01 & 0.05 & 0.15 & 0.15 & 0.03 & 0.02 & 0.10 & 0.05 \\
\hline A11 & 0.19 & 0.00 & 0.01 & 0.00 & 0.00 & 0.00 & 0.00 & 0.00 & 0.00 & 0.16 & 0.05 & 0.16 & 0.01 & 0.02 & 0.03 & 0.15 \\
\hline A12 & 0.20 & 0.01 & 0.02 & 0.00 & 0.00 & 0.00 & 0.00 & 0.00 & 0.00 & 0.15 & 0.17 & 0.07 & 0.01 & 0.13 & 0.03 & 0.17 \\
\hline A13 & 0.16 & 0.04 & 0.15 & 0.00 & 0.00 & 0.00 & 0.01 & 0.07 & 0.09 & 0.05 & 0.03 & 0.03 & 0.03 & 0.05 & 0.09 & 0.11 \\
\hline A14 & 0.21 & 0.01 & 0.07 & 0.00 & 0.00 & 0.00 & 0.00 & 0.00 & 0.00 & 0.19 & 0.18 & 0.18 & 0.01 & 0.02 & 0.03 & 0.17 \\
\hline A15 & 0.12 & 0.14 & 0.14 & 0.00 & 0.00 & 0.00 & 0.01 & 0.01 & 0.09 & 0.04 & 0.02 & 0.02 & 0.02 & 0.01 & 0.03 & 0.08 \\
\hline A16 & 0.18 & 0.01 & 0.02 & 0.00 & 0.00 & 0.00 & 0.00 & 0.00 & 0.01 & 0.16 & 0.13 & 0.11 & 0.01 & 0.01 & 0.10 & 0.04 \\
\hline
\end{tabular}

Table 3 Total impact matrix $T$

Table 4 Calculation results of influencing factors

\begin{tabular}{|c|c|c|c|c|c|c|c|c|c|c|c|c|c|c|c|c|}
\hline & A1 & A2 & A3 & A4 & A5 & A6 & A7 & A8 & A9 & A10 & A11 & A12 & A13 & A14 & A15 & A16 \\
\hline$R$ & 0.16 & 0.42 & 0.82 & 0.46 & 0.25 & 1.81 & 0.81 & 0.66 & 0.95 & 0.79 & 0.78 & 0.94 & 0.90 & 1.10 & 0.75 & 0.78 \\
\hline$C$ & 1.94 & 0.78 & 1.25 & 0.12 & 0.00 & 0.00 & 0.30 & 0.36 & 0.53 & 1.50 & 1.16 & 1.12 & 0.71 & 0.56 & 0.84 & 1.21 \\
\hline$F$ & 2.09 & 1.20 & 2.06 & 0.58 & 0.25 & 1.81 & 1.10 & 1.02 & 1.47 & 2.29 & 1.94 & 2.07 & 1.62 & 1.66 & 1.59 & 1.99 \\
\hline$J$ & -1.78 & -0.36 & -0.43 & 0.34 & 0.25 & 1.81 & 0.51 & 0.30 & 0.42 & -0.72 & -0.37 & -0.18 & 0.19 & 0.54 & -0.09 & -0.43 \\
\hline
\end{tabular}




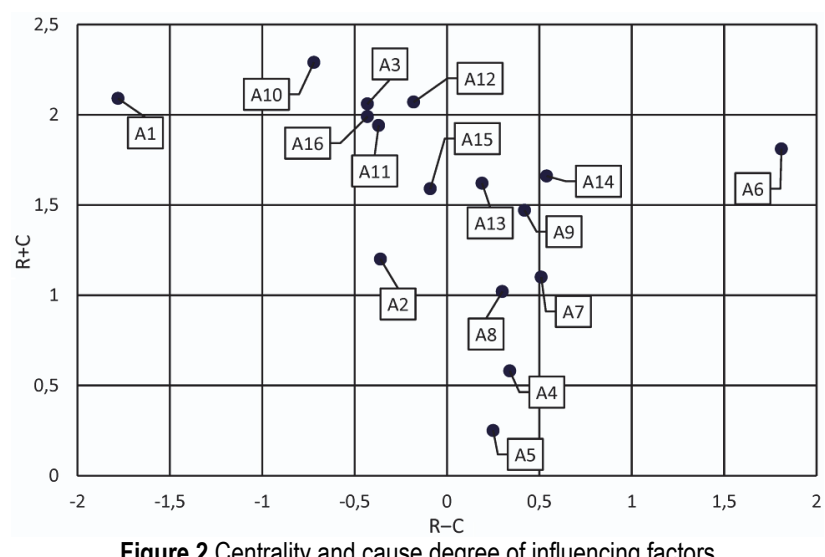

Figure 2 Centrality and cause degree of influencing factors

\subsection{Analysis of Factor Calculation Results}

Centrality is the composite value of the influenced degree of a factor by other factors and on other factors; it denotes the relevance between this factor and other factors. The higher the centrality of a factor, the greater its importance degree is. As seen in Tab. 4, the factors with high centrality $\mathrm{F}$ include $\mathrm{A} 10$ participatory governance, $\mathrm{A} 1$ quality perception, $\mathrm{A} 12$ operating system, $\mathrm{A} 3$ reasonability of charges, A16 service tangibility, and A11 service system, to name a few, all of which are closely related to community residents. As seen from Fig. 3, most of these factors are located in the middle, serving as a connecting link between the preceding and the following. The factors with low centrality are A5 professional value, A4 professional quality, A8 resource support, and A7 development standard, which are relatively independent and not easily affected by other factors. The factors with low centrality are concentrated in the dimensions of service subject and government role, indicating that these two dimensions have little influence on the service quality of smart community. As shown in Fig. 3, these factors are nearly unrelated to other factors, thus also proving the abovementioned point.

The factors with positive cause degree $\mathrm{J}$ are causal factors. According to their values, the order is as follows: A6 legal guarantee, A14 digital service, A7 development standard, A9 development theme, A4 professional quality, A8 resource support, A5 professional value, and A13 basic service. As can be observed from Fig. 2, these factors are all located at the right side of coordinate axis. Through analysis, A6 legal guarantee has the maximum influence on other factors, belonging to a root factor and accords with the expected result of expert group. A4 professional quality and A5 professional value belong to the dimension of service subject, which directly faces the community residents and provides services needed by residents as the direct provider and administrator of community services. Professional quality means the ability of service personnel to provide high-quality community services for residents. Professional value refers to the added value that can be brought by this occupation to employees and can elevate the employees' values while satisfying their own needs. The improvement of the two can both improve employees' working attitudes and objective service quality. In addition, as the transition layer between community and company, service subject is also responsible for ensuring an unblocked communication channel. As supportive factors,
A7 development standard, A8 resource support, and A9 development theme are generally decided by the local government or company without being easily influenced by the residents. Furthermore, as these three factors have many contents, they can scarcely be changed in practice. A14 digital service, which is one of the most special services, is influenced by many external factors, such as local economy, policies, scientific development, and technical reference, to name a few. This factor is also the most important difference between smart and traditional communities, and the development of this aspect should be the concern of community administrators. However, we should place the digital services behind the resident needs to avoid the mismatching phenomenon between actual resident needs and digital services.

The factors with negative cause degree $\mathrm{J}$ are, namely, result factors, located at the left side of coordinate axis in Fig. 2. Sorting according to the absolute value, the order is as follows: A1 quality perception, A10 participatory governance, A3 reasonability of charges, A16 service tangibility, A11 service system, A2 service expectation, A12 operating system, and A15 expected service. A1 quality perception directly decides the proprietors' evaluation on the service quality and is largely influenced by other factors. A2 service expectation and A3 reasonability of charges belong to the dimension of service subject. Owing to the particularity of these factors, the two factors are highly affected by subjective factors such as proprietors' social experience, economic status, and past experience, among others, and they can be hardly quantified. However, the improvement of the two factors will considerably improve the proprietors' perception for the services and generate positive influence on the improvement of service quality. A10 participatory governance, A11 service system, and A12 operating system belong to the dimension of management system. As seen from Fig. 3, these factors are in the middle of the influence structure model, serving as a connecting link between the preceding and the following which also conforms to the practical situation in China's community management system. A16 service tangibility exerts its effect by expanding the residents' perception for services. This factor, if improved, will facilitate the residents to perceive service quality but not deeply. Meanwhile, excessive negative impacts will not be generated when this factor is neglected. A15 expected service is influenced by users' subjective and external environmental factors. Notably, resident expected services will change with their needs.

\subsection{ISM Model-Based Influence Hierarchy and Influence Path Analysis}

(1) Establishment of interpretative structural model:

The value of $\lambda$ was selected multiple times, with 0.14 as the final choice. $\lambda$ was substituted into Eq. (3) and Eq. (4) to obtain the adjacency matrix $\boldsymbol{K}$. The reachable matrix $\boldsymbol{U}$ can be obtained through multiple iterative operations of adjacency matrix $\boldsymbol{K}$ as seen in Tab. 5 .

Through the computational analysis, the influencing factors of smart community service quality show hierarchical features, including the five following layers (the calculation process neglected). The first layer: A1, A2, 
A4, A5, A8, A9. The second layer: A10, A11, A12, A16. The third layer: A3, A14. The fourth layer: A7, A13, A15. The fifth layer: A6.

According to the previous analysis, an interpretative structural model was established as shown in Fig. 3. The factors in the same row mean that these factors are located at the same layer, the factors in the same divided region belong to the same influence level, and the arrows represent the influence path and direction between factors (e.g., $\mathrm{A} 6 \rightarrow \mathrm{A} 13 \rightarrow \mathrm{A} 3 \rightarrow \mathrm{A} 10 \rightarrow \mathrm{A} 1$ ).

Table 5 Reachable matrix $\boldsymbol{U}$ of influencing factor

\begin{tabular}{|c|c|c|c|c|c|c|c|c|c|c|c|c|c|c|c|c|}
\hline & $\Delta 1$ & 42 & 43 & 44 & 45 & $\Delta 6$ & 77 & 48 & 90 & $A 10$ & $A 11$ & 412 & 412 & $\Delta 14$ & 115 & $\$ 16$ \\
\hline A1 & 1 & 0 & 0 & $\frac{\mathrm{A} 4}{0}$ & $\frac{\text { AJ }}{0}$ & $\frac{\text { AO }}{0}$ & $\begin{array}{c}\text { A } / \\
0\end{array}$ & $\frac{\text { Ao }}{0}$ & $\begin{array}{c}\text { A9 } \\
0\end{array}$ & $\frac{\text { A10 }}{0}$ & $\frac{\text { A11 }}{0}$ & $\frac{1}{0}$ & $\begin{array}{c}\text { A13 } \\
0\end{array}$ & $\frac{\text { A14 }}{0}$ & $\frac{\text { A15 }}{0}$ & $\frac{\text { Alb }}{0}$ \\
\hline A2 & 0 & 1 & 0 & 0 & 0 & 0 & 0 & 0 & 0 & 0 & 0 & 0 & 0 & 0 & 0 & 0 \\
\hline A3 & 1 & 0 & 1 & 0 & 0 & 0 & 0 & 0 & 0 & 1 & 1 & 1 & 0 & 0 & 0 & 1 \\
\hline A4 & 0 & 0 & 0 & 1 & 0 & 0 & 0 & 0 & 0 & 0 & 0 & 0 & 0 & 0 & 0 & 0 \\
\hline A5 & 0 & 0 & 0 & 0 & 1 & 0 & 0 & 0 & 0 & 0 & 0 & 0 & 0 & 0 & 0 & 0 \\
\hline A6 & 1 & 0 & 1 & 0 & 0 & 1 & 0 & 0 & 1 & 1 & 1 & 1 & 1 & 0 & 0 & 1 \\
\hline A7 & 1 & 1 & 1 & 0 & 0 & 0 & 1 & 0 & 0 & 1 & 1 & 1 & 0 & 0 & 0 & 1 \\
\hline A8 & 0 & 0 & 0 & 0 & 0 & 0 & 0 & 1 & 0 & 0 & 0 & 0 & 0 & 0 & 0 & 0 \\
\hline A9 & 0 & 0 & 0 & 0 & 0 & 0 & 0 & 0 & 1 & 0 & 0 & 0 & 0 & 0 & 0 & 0 \\
\hline A10 & 1 & 0 & 0 & 0 & 0 & 0 & 0 & 0 & 0 & 1 & 1 & 1 & 0 & 0 & 0 & 1 \\
\hline A11 & 1 & 0 & 0 & 0 & 0 & 0 & 0 & 0 & 0 & 1 & 1 & 1 & 0 & 0 & 0 & 1 \\
\hline A12 & 1 & 0 & 0 & 0 & 0 & 0 & 0 & 0 & 0 & 1 & 1 & 1 & 0 & 0 & 0 & 1 \\
\hline A13 & 1 & 0 & 1 & 0 & 0 & 0 & 0 & 0 & 0 & 1 & 1 & 1 & 1 & 0 & 0 & 1 \\
\hline A14 & 1 & 0 & 0 & 0 & 0 & 0 & 0 & 0 & 0 & 1 & 1 & 1 & 0 & 1 & 0 & 1 \\
\hline A15 & 1 & 1 & 1 & 0 & 0 & 0 & 0 & 0 & 0 & 1 & 1 & 1 & 0 & 0 & 1 & 1 \\
\hline A16 & 1 & 0 & 0 & 0 & 0 & 0 & 0 & 0 & 0 & 1 & 1 & 1 & 0 & 0 & 0 & 1 \\
\hline
\end{tabular}

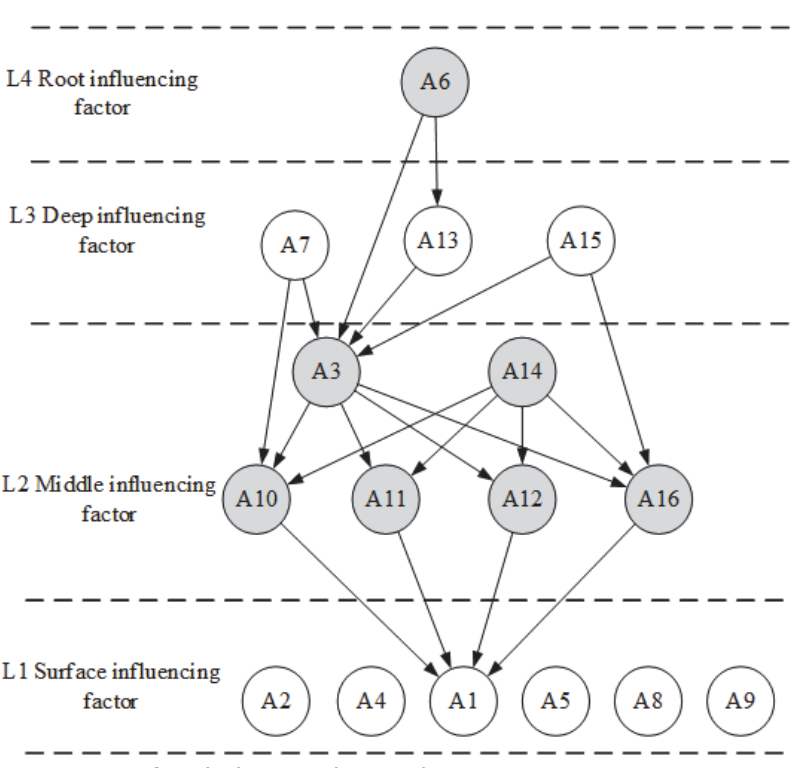

Figure 3 ISM of influencing factors of smart community service quality

(2) Analytical hierarchy process:

L1 layer presents the surface-layer influencing factors, including A1 quality perception, A2 service expectation, A4 professional quality, A5 professional value, A8 resource support, and A9 development theme. This conclusion is also consistent with the result of DEMATEL model. The surface-layer factors directly decide the smart community service quality. As observed, the surface-layer influencing factors are concentrated at two dimensions: service object and service subject. By observing Fig. 3, the residents' perception of community services should be enhanced no matter which method is adopted by the smart community to improve service quality.

L2 layer denotes the middle-layer influencing factors, including A3 reasonability of charges, A10 participatory governance, A11 service system, A12 operating system, A14 digital service, and A16 service tangibility. The middle-layer factors promote the surface-layer factors such as quality perception and service expectation but are also influenced by the upper-layer factors. Although the service contents of smart community are digital services, the management contents are still inclined to human management. Thus, perfecting the management system can indirectly improve service quality. A14 digital service and A16 service tangibility can "visualize" the service contents and make it easier for residents to perceive the service contents. A13 reasonability of charges will affect the resident expectations on community services. Any deviation will affect the residents' perception toward community services.

L3 layer denotes the deep-layer influencing factors, including A7 development standard, A13 basic service, and A15 expected service. A7 development standard is usually formulated by the local government, being able to ensure a lower limit of service content, service quality, employees' wages, and legal guarantee. A13 basic service is the most fundamental and important part in the service content, as it directly decides the upper and lower limits of other services and objective quality of community services. A15 expected service improves the positive perception of residents for services by providing services with the highest expectation value. Owing to the different social backgrounds of residents, the content of expected services also varies greatly.

The L4 layer only contains one influencing factor-A6 legal guarantee, which is a root influencing factor. This finding coincides with the DEMATEL model results and prediction of the expert group. In China, a country with relatively perfect legal system, the effect of the latter is much stronger than the rule by virtue. Therefore, the local government should elevate the legislation to the strategic development status to form an effective path, which promotes the development by law and perfects the law through the development.

(3) Influence path analysis:

Multiple influence paths exist in the interpretative structural model (Fig. 3). As many influence relations exist among the influencing factors, an excessive number of weak influence paths were filtered while drawing Fig. 3. Accordingly, the main relations are considered in this study as shown in Fig. 3. The main path is A6 legal 
guarantee $\rightarrow$ A13 basic service $\rightarrow$ A3 reasonability of charges $\rightarrow$ (A10 participatory governance, A11 service system, A12 operating system, A16 service tangibility) $\rightarrow$ A1 quality perception. The legislation provides a guarantee for the infrastructure construction in smart community, and the infrastructure construction further promotes the perfection of service and management systems. The perception of residents for community services is further expanded by participatory governance and service tangibility. This process is not only the idea followed in the practical smart community construction in China but also the most effective path to improve smart community service quality.

In addition, many other influence paths exist, including A6 legal guarantee $\rightarrow$ A3 reasonability of charges $\rightarrow$ (A10 participator governance, A11 service system, A12 operating system, A16 service tangibility) $\rightarrow$ A1 quality perception. The law guarantees the reasonability of fees charged by the property management company and affects the perception of residents for community services. Furthermore, non-root factors also influence the community service quality via all kinds of influence paths, such as A7 development standard $\rightarrow$ A10 participatory governance $\rightarrow$ A1 quality perception. The rights of residents to know and vote are stipulated by the government. Before an activity is carried out, the opinions will be solicited from community residents so that it can better conform to their needs.

The improvement schemes of specific factors can also be found in the interpretative structural model. For instance to improve A10 participatory governance, the main factors influencing it can be found along the straight line in Fig. 3. The law guarantees the right of residents to know in the community activity and provides a legal guarantee for participatory governance. Defining perfect development goals will have profound significance for residents to participate in the management. In addition, the needs of residents to participate in realizing the development goals can also facilitate the property management company to maintain good contact with residents. Reasonable charges will contribute to the improvement of impressions left by the property management company on residents and motivate them to participate in property management.

\section{DISCUSSION}

The influencing factors of smart community service quality were extracted through the Delphi and literature methods. Sixteen basic influencing factors (Tab. 1) were selected from 5 dimensions: service object, service subject, government role, management system, and service content. Scholars have widely recognized most of the influencing factors, such as perception of community residents, service expectation, participatory governance, and expected service, to name a few. We also realize the cross-validation with the research results obtained by other scholars. Meanwhile, new influencing factors were determined, including reasonability of charges, development standard, and service tangibility, among others.

According to the calculation thought of the DEMATEL model, the centrality and cause degree (Tab. 4) of each influencing factor were calculated. The research results verified the security effect of laws and regulation which was basically consistent with those obtained by other scholars. On this basis, the root influence of legal guarantee on the smart community service quality was further verified. Therefore, this study suggested that the local government should elevate the formulation and perfection of related laws and regulations to the strategic development status, thus providing a momentum for the development of smart community. Meanwhile, the importance degree of each influencing factor was judged through Tab. 4: the higher the centrality degree of a factor, the higher its importance degree. The factors with high centrality include A10 participatory governance, A1 quality perception, A12 operating system, and A3 reasonability of charges, among others, most of which are directly related to community residents. Hence, when implementing the construction or providing services, smart community should prioritize the needs and actual perception of community residents and determine the development sequence of services according to those needs. Meanwhile, importance should also be attached to the maintenance of network platforms such as cloud platforms and smart programs, and the stability and smoothness of feedback channel and communication channel should be ensured.

Following the calculation results in Tab. 4, the research results were further visualized (Fig. 2). The causal factors are located at the right side of coordinate axis, including A6 legal guarantee, A14 digital service, and A7 development standard, etc. The result factors are located at the left side of coordinate axis, including A1 quality perception, A10 participatory governance, A3 reasonability of charges, etc., and the result factors are affected by the causal factors. Therefore, priority should be given to the improvement of causal factors during the optimization of smart community services. Meanwhile, the action mechanism of influencing factors was further investigated on the research basis of other scholars, and the interaction between influencing factors was clarified.

Based on the calculation results of the DEMATEL model, the influencing factors were further hierarchically divided (Fig. 3) through the ISM model into root, deeplayer, middle-layer, and surface-layer influencing factors. The concrete influence paths of influencing factors were also embodied in Fig. 3, and the smart community service quality and single influencing factor could be improved according to the influence path. As observed from Fig. 3, the factors in the dimension of management system were mostly located at the middle layer and are playing key roles. Therefore, community administrators should regulate the direct influencing factors via the management model and indirectly promote the improvement of community service quality.

\section{CONCLUSIONS}

The service quality of smart community, which is a new-type community service mode, directly decides the recognition degree of community residents for community construction and the main community construction direction. To achieve accurate evaluation and effective improvement of smart community service quality, the DEMATEL-ISM model was used to determine the influence relation and influence intensity between factors. 
An interpretative structural model was constructed, and the root, deep-layer, middle-layer, and surface-layer influencing factors were distinguished. The following conclusions were obtained:

(1) The DEMATEL-ISM model can better distinguish the cause and result degrees of influencing factors for smart community service quality. The legal guarantee, digital service, development standard, and development theme, among others, have high cause degree. Meanwhile, quality perception, participatory governance, reasonability of charges, and service tangibility, to name a few, have high result degree. The factors with high cause degree exert influence on those with high result degree.

(2) The DEMATEL-ISM model can be used to accurately divide the influence hierarchy of influencing factors of smart community service quality. Legal guarantee is a root influencing factor. Development standard, basic service, and expected service are deep-layer influencing factors. Reasonability of charges, participatory governance, service system, operating system, digital service, and service tangibility are middle-layer influencing factors. Quality perception, service expectation, professional quality, professional value, resource support, and development theme are surface-layer influencing factors.

(3) With its capability to deeply analyze the influence relation and concrete action mechanism between influencing factors of smart community service quality, the DEMATEL-ISM model is a simple and effective model used to objectively evaluate the quality of services provided by the smart community.

The study results serve as the cause-and-effect diagram of influencing factors of smart community service quality and interpretative structural model. The cause and result factors were differentiated and the influence hierarchy and influence paths of influencing factors divided, thus providing an accurate theoretical support for the evaluation and improvement of smart community service quality. However, the concrete improvement path of single factor and quantification of influencing factors continue to require further exploration.

\section{REFERENCES}

[1] Xu, Z. Y. \& Zhang, L. (2019). The precision of public services: innovation of urban community governance mechanism. Journal of Central China Normal University (Humanities and Social Sciences), 58(4), 19-27. https://doi.org/10.3969/j.issn.1000-2456.2019.04.004

[2] Anrong, D., Li, G., Li, J., \& Kong, X. (2016). Research on smart community planning of yishanwan, china towards new urbanization. IRSPSD International, 4(1), 78-90. https://doi.org/10.14246/irspsd.4.1_78

[3] Wang, W. M. (2019). The comparison and reference of wisdom community building at home and abroad. Journal of Jiangxi Science \& Technology Normal University, 1, 79-84. https://doi.org/10.3969/j.issn.1007-3558.2019.01.012

[4] Wang, F. S. (2020). Intelligent community governance: analysis framework and multi case comparative study. Chinese Public Administration, 12, 76-83. https://doi.org/10.19735/j.issn.1006-0863.2020.12.10

[5] Xu, X. Y. (2019). Resource shortage or resource dependence: resource dilemma in intelligent community old-age services. Lanzhou Academic Journal, 5, 196-208. https://doi.org/10.3969/j.issn.1005-3492.2019.05.018

[6] Zi, M. \& Tang, Z. (2020). Construction of community sports service system for the aged under the background of "Healthy Heilongjiang". International Journal of Social Science and Education Research, 3(5), 26-29.

[7] Sun, Y., Song, H., Jara, A. J., \& Bie, R. (2016). Internet of things and big data analytics for smart and connected communities. IEEE Access, 4, 766-773. httsp://doi.org/10.1109/ACCESS.2016.2529723

[8] Lunzhi, D. (2020). Anonymous certificateless multi-receiver encryption scheme for smart community management systems. Soft Computing, 24(1), 281-292. https://doi.org/10.1007/s00500-019-04375-8

[9] Wheeler, C. A., (2016). Barriers to community development in distressed cities: A case study of Camden, New Jersey. Community Development, 47, 496-513. https://doi.org/10.1080/15575330.2016.1202295

[10] Yang, Y. L. \& Liu, S. F. (2020). Research on the optimization of public service supply by the construction of smart community: A case study of Junmen community in Fuzhou. Journal of Fuqing Branch of Fujian Normal University, 4, 34-39.

[11] Wang, K., Sun, S. H., \& Xu, R. L. (2020). Research on precise supply of community public services: Micro-logic and fine way. Journal of Fuyang Normal University (Social Science), 1, 109-117. https://doi.org/10.14096/j.cnki.cn341044/c.2020.01.19

[12] He, J. X. \& Shao, Y. L. (2019). Three-dimensional model of intelligent supply in community public service and construction of operating mechanism system. Journal of Gansu Administration Institute, 1, 64-75. https://doi.org/10.3969/j.issn.10094997.2019.01.008

[13] Hutchings, P., Chan, M. Y., Cuadrado, L., Ezbakhe, F., Mesa, B., Tamekawa, C., \& Franceys, R. (2015). A systematic review of success factors in the community management of rural water supplies over the past 30 years. Water Policy, 17(5), 963-983. https://doi.org/10.2166/wp.2015.128

[14] Chowns, E. (2015). Is community management an efficient and effective model of public service delivery? Lessons from the rural water supply sector in Malawi. Public Administration and Development, 35(4), 263-276. https://doi.org/10.1002/pad.1737

[15] Qian, K. (2020). Application of intelligent technology in community governance: theoretical construction and practice analysis. Contemporary Economic Management, 42(4), 64-70.https://doi.org/10.13253/j.cnki.ddjjgl.2020.04.010

[16]Goethem, A., Hoof, A. V., Castro, B., \& Marcel, A. G. (2014). Quality is key: the impact of community service, community service quality, and reflection on adolescents' volunteering intentions. International Journal of Developmental Sciences, 8(3), 137-147. https://doi.org/10.3233/DEV-14145

[17] Crittenden, R. \& Everson, T. (2021). Yakima, COVID-19 in the Community. The Journal of Ambulatory Care Management, 44(1), 76-77. https://doi.org/10.1097/JAC.0000000000000366

[18]Li, X., Lu, R., Liang, X., Shen, X., Chen, J., \& Lin, X. (2011). Smart community: An internet of things application. IEEE Communications Magazine, 49(11), 68-75. https://doi.org/10.1109/MCOM.2011.6069711

[19] Lee, Y. T., Hsiao, W. H., Huang, C. M., \& Chou, T. S. (2016). An integrated cloud-based smart home management system with community hierarchy. IEEE Transactions on Consumer Electronics, 62(1), 1-9. https://doi.org/10.1109/TCE.2016.7448556

[20] Abeysiriwardhana, W., Wijekoon, J. L., \& Nishi, H. (2020). Smart Community Edge: Stream Processing Edge Computing Node for Smart Community Services. IEEJ Transactions on Electronics Information and System, 140(9), 1030-1039.https://doi.org/10.1541/ieejeiss.140.1030

[21] Farooqi, N., Gutub, A., \& Khozium, O. (2019). Smart Community Challenges: Enabling IoT/M2M Technology Case Study. Life Science Journal, 16(7), 11-17. 
https://doi.org/10.7537/marslsj160719.03

[22] Sibai, O., Valck, K. D., Farrell A. M., \& Rudd, M. J. (2015). Social control in online communities of consumption: A framework for community management. Psychology \& Marketing, 32(3), 250-264. https://doi.org/10.1002/mar.20778

[23] Anshari, M., Arine, M. A., Nurhidayah, N., Aziyah, H., \& Salleh, M. H. A. (2021). Factors influencing individual in adopting eWallet. Journal of Financial Services Marketing, 26(1), 10-23. https://doi.org/10.1057/s41264-020-00079-5

[24] Rodriguez Lluesma, C., García Ruiz, P., \& Pinto Garay, J. (2021). The digital transformation of work: A relational view. Business Ethics: A European Review, 30(1), 157-167. https://doi.org/10.1111/beer.12323

[25] Yamagata, Y., Murakami, D., Wu, Y., Yang, P. P., Yoshida, T., Binder, R. (2019). Big-data analysis for carbon emission reduction from cars: Towards walkable green smart community. Energy Procedia, 158, 4292-4297. https://doi.org/10.1016/j.egypro.2019.01.795

[26] Parmentier, G. \& Mangematin, V. (2014). Orchestrating innovation with user communities in the creative industries. Technological Forecasting and Social Change, 83(1), 40-53. https://doi.org/10.1016/j.techfore.2013.03.007

[27] Gust, S. \& Seifer, S. (2011). The central role of governance in community-based participatory research. Progress in Community Health Partnerships Research Education \& Action, 5(2), 105. https://doi.org/10.1353/cpr.2011.0023

[28] Altschuler, D. \& Corrales, J. (2012). The spillover effects of participatory governance: Evidence from communitymanaged schools in Honduras and Guatemala. Comparative Political Studies, 45(5), 636-666. https://doi.org/10.1177/0010414011427133

[29] Chen, L. W. \& Zhao, S. W. (2018). Research on smart community operation management system and platform construction from the stakeholders' view. Contemporary Economic Management, 40(8), 37-42. https://doi.org/10.13253/j.cnki.ddjigl.2018.08.007

[30] Abrahamson, K., Myers, J., Arling, G., Davila, H., Mueller, C., Abery, B., \& Cai, Y. (2016). Capacity and readiness for quality improvement among home and community: Based service providers. Home Health Care Services Quarterly, 35(3-4), 182-196. https://doi.org/10.1080/01621424.2016.1264343

[31] Wylie, K., Davidson, B., Marshall, J., Bampoe, J. O., Amponsah, C., \& McAllister, L. (2019). Community service providers' roles in supporting communication disability rehabilitation in Majority World contexts: An example from Ghana. International Journal of Speech-Language Pathology, 22(4), 414-424. https://doi.org/10.1080/17549507.2019.1651395

[32] AL-Ghaswyneh, O. F. M. (2020). Marketing universities' services role in providing financial resources. Journal of Financial Services Marketing, 25(3), 65-75. https://doi.org/10.1057/s41264-020-00075-9

[33] Shakeri, H. \& Khalilzadeh, M. (2020). Analysis of factors affecting project communications with a hybrid DEMATELISM approach (A case study in Iran). Heliyon, 6(8), e04430. https://doi.org/10.1016/j.heliyon.2020.e04430

[34]Tsantilas, S., Spandonidis, C., Giannopoulos, F., et al. (2020). A comparative study of wireless communication protocols in a computer vision system for improving the autonomy of the visually impaired. Journal of Engineering Science \& Technology Review, 13(1), 72-76. https://doi.org/10.25103/jestr.131.10.

[35] Yang, D., Sun, Y., \& Wu, K. (2020). Assembly reliability modelling technology using function decomposing and LSSVM. International Journal of Simulation Modelling, 19(2), 334-345. https://doi.org/10.2507/IJSIMM19-2-CO9

\section{Contact information}

Fengke WANG, Associate Professor Henan University of Science and Technology, No.263, Kaiyuan Avenue, Luolong District, Luoyang, Henan, 471000, China

E-mail: fengkewang@126.com

Juzheng ZHANG, Graduate student Henan University of Science and Technology, No.263, Kaiyuan Avenue, Luolong District,

Luoyang, Henan, 471000, China

E-mail: 2489684930@qq.com

Panke ZHANG, PhD

(Corresponding author)

Henan University of Science and Technology, No.263, Kaiyuan Avenue, Luolong District,

Luoyang, Henan, 471000, China

E-mail: cnzpk@163.com 